\title{
Nature's guide for mentors
}

\section{Having a good mentor early in your career can mean the difference between success and failure in any field. Adrian Lee, Carina Dennis and Philip Campbell look at what makes a good mentor.}

The Nature awards for creative mentoring in science were created on the premise that the mentorship of young researchers - although fully deserving of recognition - is perhaps the least remarked on of all the activities that take place in the lab. Indeed, there is no established definition of what constitutes good scientific mentoring. This article attempts to remedy that situation, drawing on the evidence from competitions for Nature's awards. These are held on a national or regional basis, with the most recent taking place last year, when the focus was on Australasia. Previous competitions have been held in the United Kingdom, and the next competition will be in South Africa (see www.nature.com/nature/ mentoringawards/southafrica/index.html).

The response to the competition in Australasia was remarkable, with more than 70 groups of 'mentees' submitting their achievements and the reasons why they believed their mentor excelled, with each of the nominated mentors giving a personal view of how they approach mentoring. The quality of applications was outstanding and the panel, all experienced in refereeing papers and grant applications, commented that this was one of the hardest evaluative tasks they had ever undertaken. However, there could be only two winners and they have been lauded elsewhere (see Nature 444, 966-968; 2006).

Having been involved in judging the awards - whether in Australia or in the United Kingdom - we realized that within the pages of the applications was an immense resource that could provide a basis for reflection on what comprises good mentoring. These reflections are presented here, with examples of just a few of the hundreds of quotable quotes included in the nominations supporting the mentors. The attributes that we highlight represent a distillation of the opinion of more than 350 scientists writing as nominated mentor or their nominating mentees (and it was the latter whose comments were all-important for the judges).

We hope that this material will be especially useful to younger scientists as they start out on their careers as mentors - be it $\mathrm{PhD}$ supervisor or scientific team leader. But others stand to benefit from it too. Indeed, we challenge readers who are established leaders of groups and supervisors of young scientists to look at the evidence of what comprises good mentoring, reflect on your practices and determine whether there are lessons here that could see you alter your approach. Such changes could be to the ultimate benefit of those under your charge and, given the lasting and broad influence of good mentors highlighted by the competition, to science as a whole.

All the quotes included here were taken word-for-word from the applications, either from proposing mentees or the mentors themselves. For obvious reasons they have been depersonalized and are unattributed.

\section{A mentor for life}

CCM, without any doubt, sees all his interactions with people as lifelong. He always keeps in touch with ex-students, postdocs and so on after they have moved on. Even if he is not directly helping them, he keeps himself aware of their activities and at times informs them of things he believes would be of interest or useful, to them. He genuinely treats his ex-students and postdocs as part of an extended family. $\mathbf{9}$
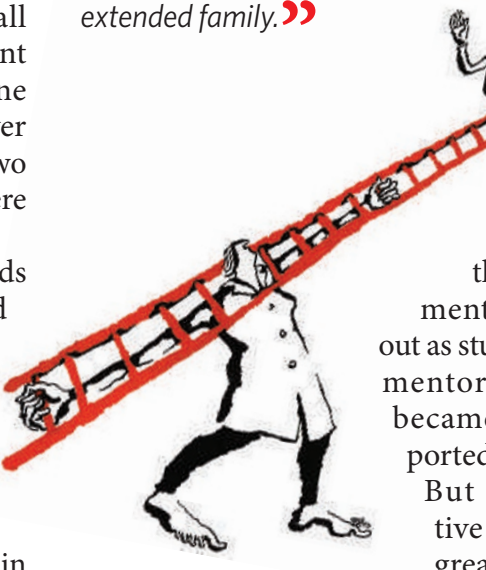
mentees started out as students of the mentors but later became well-supported colleagues. But a distinctive feature of a great mentor as opposed to a great supervisor seemed to be a special focus on helping to build the mentee's career. A natural consequence of the care and effort the mentors put into supporting the careers of their students/staff was that the majority of them became mentors for life: their advice continued to be valued, friendships grew and the links were maintained.

C(For me there is a difference between a supervisor and a mentor. With the latter you find that you are not simply a student with a research project, but a student with a career in front that the mentor helps you start. 9

\section{Personal characteristics} Enthusiasm

CGirst and foremost, $M$ is incredibly passionate about science. She eats, sleeps and breathes science. Her enthusiasm is absolutely infectious, and it creates a wonderful atmosphere in her laboratory. $)$

$\mathbf{C}$ It is the nature of supervision that you have to explain/teach some key concept time after time as each new student arrives. Each time I had to make it feel to the student postdoc that it was the first time I had ever explained the concept; each time I had to tell it with sparkle to help inspire them to seek to know more. At times it was hard to stay 'inspirational'; but to fail would have meant to me that I should quit as a supervisor. You need to understand, as an old and wise friend once said to me, 'Remember, they stay the same age, you get older!')

Passion, enthusiasm and positivity were words dominating the majority of the mentee reports. Whether these are traits we can cultivate or create is debatable. The lesson seems to be that it is very important to be as enthusiastic about your students' research as you are about your own. If you are not, then the question becomes: is the student working on the correct project? If you are not passionate about their project, how can you properly support them? This should also be a lesson to administrators, who may sometimes allocate students to projects and supervisors for expediency rather than a genuine concern for the student or indeed the staff member.

\section{Sensitivity}

CCWhen things go wrong, it is important to find out why things happened the way they did. There could be personal factors (sickness, relationship break-ups) that contribute to unhappy decisions or results. Although I may not be able to provide the solution to personal problems, I can provide a sympathetic ear as well as advice or direction to support services. $\$$

This quote speaks for itself but there were a number of examples in which mentors were 
very sensitive to their charge's circumstances and showed compassion and understanding. When a student or colleague exhibits unusual behaviour or lack of progress there will be a reason. Mentors need to listen, hear and support. Also, many mentors were sensitive to mentees' needs that were not strictly professional, such as finding the right balance between work and family responsibilities; coping with cultural transitions after a move from a different part of the world; developing confidence in a culture that may not be welcoming; or opposing ethnic or gender bias if it arises.

CCM also knows that it is important to have a work-life balance. He's made it easy for a postdoc with young children to return to the lab part time. It's encouraging as a young scientist to see that there are lab heads who are supportive of people being able to spend time with their family but still have a chance to develop their careers. 99

\section{Appreciating individual differences}

CCAgain it is important to cater for personal traits. Some of my student colleagues need to dot every $i$ and cross every $t$ as they design a set of critical experiments that we have all agreed are important. Others, with, I suspect, an equal success rate, need to jump in, risk making a mess of a few highly critical experiments but gain an instant understanding of either what not or what to try. Allowing both approaches is sometimes difficult, but necessary. 99

We are all different in how we work and in what motivates us. The mentees were clearly very appreciative of an ability to carefully craft development activities to enhance and extend personal strengths. Special effort is needed to try to understand all those in a team and deal with them differently. And however much you want that student/colleague to work on that project, sometimes you have to help them make decisions about their career directions.

CCNot everybody wants to be a leading researcher and some have skills that make them better suited to other occupations. There is little point in encouraging young people to take on a career to which they may be unsuited or that they will find stressful or uninteresting. So I believe it is
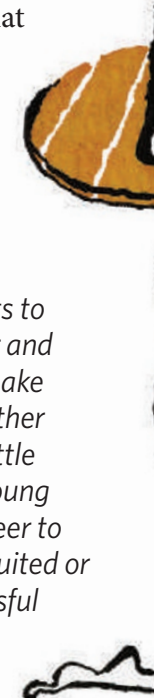

necessary sometimes to encourage them into other directions. $)$

\section{Respect}

CSShe treats her colleagues, regardless of whether they are doing a PhD or if they are a fellow professor, with the same high regard. In doing so, $M$ inspires confidence in her collaborators. 9

It is sadly true that laboratories exist where the PhD students are seen as extra pairs of hands rather than genuine collaborators. Although the supervisors may well be successful and grants be funded courtesy of those extra hands, they will never have the satisfaction of working in the stimulating environments described in all of the applications for the mentor awards and will never truly be respected themselves.

\section{Unselfishness}

CCHis magnanimity in sharing his own ideas and delight in seeing others succeed has also been an inspiration, not just for myself but for a whole generation of younger scientists. 99

CCMost importantly, M has no intellectual jealousy. She was always happy to see others succeed, pushing them forward into the limelight while standing back in the shadows herself. 95

There are leaders of some big and important groups who are more concerned with using group members to promote their own scientific standing. Letting your students/colleagues take your ideas and run with them, and being free and willing for them to take credit is not always easy but is always appreciated. What do you lose by allowing them to be lead authors even if the idea was yours?

\section{CCHis lack of}

defensiveness was very important to me. On several occasions I've published papers that were critical of some aspect of his work - and he helped me to articulate the issues and

supported me in getting them published. $)$

CCI believe that it is too easy

for mentors to create grand (manipulative) plans for their younger colleagues.
I believe it is important for mentors to suppress the desire to paint the grand picture, instead it is imperative that they learn to understand their colleagues and how to assist them to fulfil their dreams. $)$

ClI was not uncommon to hear that she had lobbied for an opportunity for a postdoc to speak at a conference rather than doing so herself because she recognized the value of becoming known, especially given our distance from North America and Europe. 99

\section{Support for other than one's own \\ C $M$ is just as diligent in fostering careers of people who he thinks can advance science as he is at fostering his own students. This action is consistent with a motive that goes beyond mere ego and represents service to the advancement of science. $\$$}

The impact of a good mentor goes far beyond his or her own boundaries. Within the applications were many examples of support outside the mentor's group. Indeed a number of the mentee support documents were from those who had never actually been in the mentor's laboratory but whose lives had nevertheless been touched.

\section{Teaching and communication \\ CCM's enthusiasm was infectious for many undergraduate students, and I have no doubt in saying that her delivery of the subject matter was instrumental in fuelling my interest in $X$ as a subject. $)$}

The tension between research and teaching remains at all universities. Success in both is not mutually exclusive and it was striking, but not surprising, that many of the exemplary mentors were exemplary teachers. Many of the mentees who themselves have gone on to very successful careers and have international reputations in science would not have gone down that pathway if they had not been exposed to their future mentor as a teacher.

Those who work in university administration need to remember the benefit of exposing undergraduate students to top scientists to increase the number of graduate students. Up-and-coming young scientists should put effort into their teaching in order to inspire and interest their future mentees. Good mentors encourage their students to teach as soon as they start their $\mathrm{PhD}$, not only to supplement their income but, more importantly, to develop skills that will benefit them in the long term.

Also, many of the great mentors were great communicators, not only of science itself but also of enthusiasm for it to diverse audiences such as schools or local societies. This is not a universal talent and can even be damaging to all concerned if done badly. The good mentors appreciated that such activities can be very valuable training for the communicator 
and encouraged their students and younger colleagues to develop these skills.

CCI first encountered $M$ as a year-11 highschool student in a small country town. The Royal Australian Chemical Institute had commissioned $M$ to travel to regional Victoria and put on a 'chemistry show'. I remember the explosions, the foam tower spilling its contents over the stage, and $M$ pretending that he hadn't noticed the chemical mayhem around him. And I remember that it was about this time that I became interested in chemistry. 9

CSStudents need experience talking about their research in many different forums. Conference attendance is crucial so that they have the opportunity to discuss with other researchers and to develop new ideas. But it is equally important that students have the opportunity to discuss their work in lay terms, whether it is being presented to parents, teachers, or to doctors and nurses as Shas done. 9

\section{Tips for mentors}

Throughout the mentees' reports and the mentors' reflections on their mentoring styles were descriptions of activities used by the mentors that contributed to their success. A number of these tips are reproduced here for those readers embarking on a scientific career - or those in full flight - in order to stimulate thinking about mentoring. There is no magic formula; these are simply examples of what the mentees thought worked for them.

\section{Availability: the open door}

CCFirst, her door is always open, even now in her retirement she can never say 'come back later'. I now greatly admire this skill for I find myself struggling with administration and feeling guilty in making appointments to see students. M always put scientific discussion first. 29

\section{CSI cannot remember him ever cancelling an appointment with me despite the tremendous demands on his time (he was head of department for some of the time that I was his student). $\boldsymbol{P}$}

\section{CCM was always accessible, and she always made it abundantly clear to her students that she would rather talk about science with them than do just about anything else. 95}

If there was one theme that came through all the reports it was this one. Availability is the standout quality appreciated by the mentees. Despite enormous workloads and responsibilities, the mentor was always there and the door was always open. They never failed to respond to an urgent request immediately. Mentees marvelled at e-mails answered in 20 minutes,

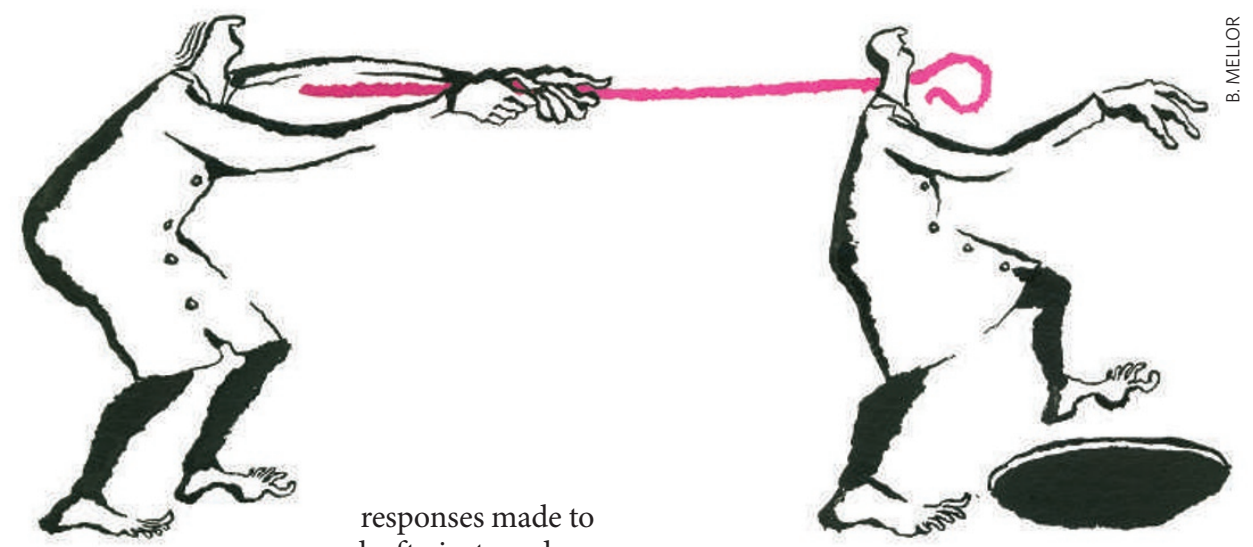

drafts in two days and the willingness to listen to their problems.

The regular meeting is clearly an important strategy that some mentors use as well as having an open door. The most impressive was the mentor who set aside a whole day to meet each group member individually for half an hour. The day included a journal-club meeting for all, followed by a research discussion over drinks at the end of the day. An advantage of having a routine that all knew was that it made it easier for students to plan their work and for the mentor to avoid committee meetings on that day. Morning or afternoon coffee breaks are also great daily opportunities for discussion. In these meetings, good mentors encouraged troubleshooting unsuccessful experiments rather than discarding them as a result of incompetence. Indeed there was a common theme that analysis of failure was as important as success.

\section{Inspiration, optimism}

CG Going to M's office with your head down, armed with a plot or calculation showing that the project seemed to be going nowhere, you will leave believing that you've solved the mysteries of the Universe. 99

CCOn many occasions I remember walking into her office convinced that I had been wasting my time, and then ten minutes later walking out with a smile and the sure knowledge that what was a bad result was indeed just what I needed!

The 'walk into the office dispirited/a failure/ miserable and yet walk out inspired and optimistic' phenomenon is a special feature of interaction with the great mentors. There were many comments similar to those above. Attributes that allowed the mentor to cause these almost spiritual experiences included: a broad vision of how science works, a bigpicture view and a conviction that unexpected results are often the most interesting and point towards novel insight.

\section{Balancing direction and self-direction}

C $M$ displays the right balance of direction in a project and letting someone discover and develop insights for themselves.
Supervisors who micromanage their students or have very specific ideas of how the science in a lab should be done can stifle the student. 99

\section{CCThe scientific acumen to, on the one} hand, encourage promising ideas and, on the other, recognize $a$ 'dead end' is one of M's great mentoring skills. $\$$

Given the large number of comments on getting the balance right, this is a major component of good mentoring. Just how much guidance to give can be a challenge. There were many negative comments about those who have been seen to micromanage. Yet there was also criticism of those who let students run free and learn by their mistakes.

The skill lies in giving young researchers the freedom to expand on their ideas but gently reining them in when they are off track. There were no clear clues as to how to develop this skill. Possibly awareness of how you do it could encourage you to change. Where do you place yourself on the direction-self-direction scale?

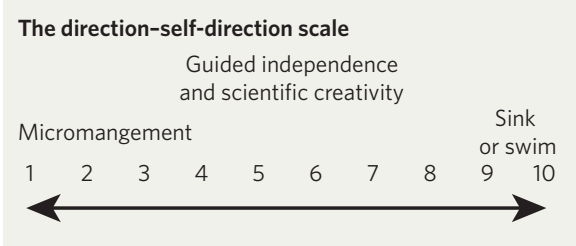

CCHis advice was almost always given in the form of suggestions, so that we were able to digest them and form our own judgment about their worth. With hindsight I recognize this as a deliberate strategy designed to encourage independence of thought and critical thinking. As a PhD student, M made me feel like his collaborator. This is probably the greatest single lesson I have tried to take from $M$ and apply to my own research group, to encourage and prompt students to follow their own ideas and judgement, and to provide an environment where this is possible. 99

A special challenge is, even if you are prepared to encourage independence, what can you do that nurtures research creativity? 
CCWhen I conducted an experiment using two different sources of the one tissue that was never in the research programme, $M$, instead of saying 'No, stick to the programme', asked me why I thought that was a good experiment to do and then complimented me for thinking laterally about the programme. $\mathbf{s}$

\section{CSIf and when your ideas did not come} to fruition there was no criticism, only encouragement to learn from the mistakes made, if any, and encouragement to develop other avenues of scientific attack. This 'judgement'-free environ allowed one to attempt to implement challenging techniques, knowing that there was no 'skin off one's nose' for trying. $\$$

\section{The art of questioning and listening}

CCThere is always another question to ask. The questions seem innocuous but nothing is as it seems to be; there are more insights to be gained by probing away. $M$ also never imposes her will, but she persistently keeps the questions flowing to help the answer come along. 29

One of the strategies used in developmental workshops to help young academics become better small-group teachers is to practise answering students' questions with a question, in order to lead them towards both an answer and a better understanding of what they are learning. It is always easier to give the answer. The same is true when you start to mentor your $\mathrm{PhD}$ students and younger colleagues.

\section{$\mathbf{C}$ Rather than directly providing me with} interesting ideas, he is able to ask the right questions to allow me to come up with my own theories and ideas. 9

This is a skill and it can be practised even though it is time-consuming. It is a skill highly valued by the mentees, as was the equally important skill of active listening.

\section{CCThe major aspects of practice and} personality are her ability to listen patiently, even when she knows better, and to point the mentored person to a more complete understanding of the issues implicit in a particular problem. This she does with deceptively simple questions that frequently do not elicit an immediate response, but ultimately allow a more rational interpretation of all the facts. $)$

\section{Being widely read and widely receptive}

CCAs a new assistant professor with my own young graduate students, I can appreciate the subtle ways in which $M$ fostered good habits of constantly surveying the literature and exploring research outside the immediate bounds of my own interests. I hope that I can guide my students in a

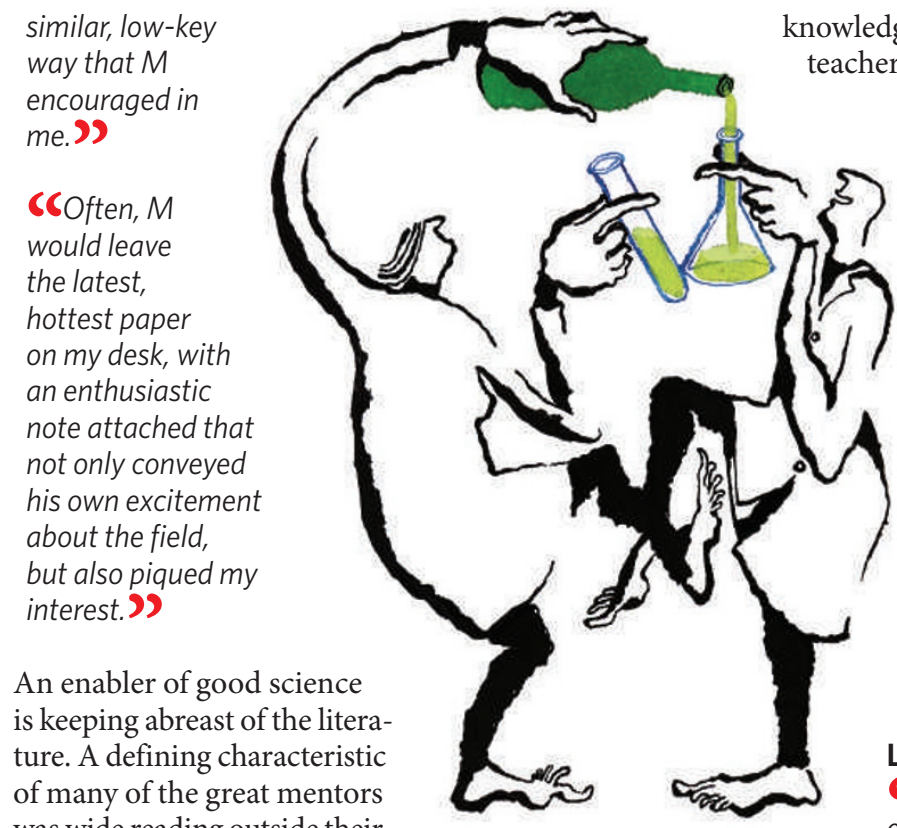
was wide reading outside their field. Mentees appreciated sharing in this reading, and also the deliberate strategy of using key papers as a base for discussion either at group or individual meetings or by the casual dropping of reprints as described above. Again, time-consuming but valued.

\section{CCFor a rigorous scientist of international acclaim, I found her to be very open-minded, and she encouraged my exploration of different avenues of research, even when these fell outside her direct expertise (if need be, $M$ was very willing to study new areas of enquiry in order to provide appropriate intellectual support). $\$$}

Most researchers have a pet hypothesis and an individual approach to their particular area of science. Sometimes that dogma and limitations in breadth may be exposed and challenged by students or colleagues. As a result, you need to be open to ideas and solutions from all other disciplines. You need to be ready to accept that you might be wrong, to acknowledge and study new directions you have never considered, and to congratulate your mentees for taking you down that pathway.

\section{The initial project}

CCEnsure that all students have projects with at least some guaranteed biologically relevant results. Risky work (such as making a knockout mouse) should be balanced with other work that will ensure some results. $)$

This is related to getting the balance right, but a number of comments highlighted the fact that, in the beginning, students do not have the experience to make a decision on the first project. One mentee drew attention to the fact that, at the start of a $\mathrm{PhD}$, it is the supervisor who has the knowledge, but as the PhD draws to a close, it is the student who has the forget to smell the roses.

I will always remember him telling me as a first-year PhD student that I needed to take up other activities besides science. My life has been a lot more fun because of his advice. $)$

This was not a widespread observation but was clearly a positive feature to those who received this advice.

\section{Celebration}

CCThe first time a person comes up with a novel idea or experiment of their own. This should be an occasion for public recognition within the lab as it is a milestone of great significance for most young scientists. $)$

The importance of celebration and rewarding successes, large and small, is often neglected. Yet it can be highly encouraging to individuals and can contribute to the building of communities. It is a strategy that all mentors can introduce, although the extent of the celebration will vary depending on personalities and level of extroversion.

The guiding principle is that celebration, however large or small, is a powerful motivator. The range of celebrations mentioned in the awards nominations is worth listing here as a challenge to your imagination: off-campus lunches, the weighing of the $\mathrm{PhD}$ thesis on submission, cakes at morning or afternoon tea, barbecues at the mentor's home or cocktail parties on graduation.

\section{Building communities}

A constant theme from the groups supporting their mentor was the sense of community. The successful mentors realized the need to build communities to create an environment where all under their care could flourish. They all had deliberate and varied strategies to build these communities. How often have 
you experienced the negative impact of silobuilding within departments? Positive and sustaining communities do not just happen, they have to be nurtured.

\section{Of scientists \\ CCM takes an inordinate amount of trouble to involve all the people around her in all aspects of the life of the lab, such as seminars, research-planning meetings and informal meetings with outside visitors. All these make you feel a valued member of the research team from the outset. $\boldsymbol{}$}

Regular meetings have been commented on before. They include: whole-group planning meetings; meetings with external visitors; subgroup meetings with a specific task to report to the whole group; group-writing tasks; assigning a new junior staff member or student to a senior staff member or student mentor.

Especially important meetings were 'journal clubs', which many team leaders set up but often do not sustain.

\section{CCThe journal club helps to make sure all of us read something other than immediately relevant research, at least once a week. The menu wanders around, sometimes classic papers, sometimes high-impact pieces in Nature or Science, sometimes chapters from a popular-science book, sometimes philosophy or psychology of science. Over time we have evolved the practice of going round the table first with each participant speaking for 3 minutes. There are always some people who have intelligent comments, but would never put them forward if it were left to them to find the right time to speak. The 3 minutes also restrains the talkative. $)$}

\section{Of people}

CCThe most useful single thing I've learned is that chocolate biscuits do more for everyone's good humour and enthusiasm than any amount of feel-good talk. The role of blood sugar should probably have been obvious to a biologist from the outset, but I only learned this by experience. Mind you, cheerful and encouraging conversations are good too, as are gin and tonic. $\$$

Again some mentors' disposition might not always lead to easy support and nurturing of a social group. But there is no doubt about how much such social activities were valued. Activities can be as simple as the chocolate biscuit or more adventurous, for example 'Shakespeare under the stars', wine tastings, ethnic dinners, dinner parties with visiting scientists, bird-watching days, video nights or celebration of every birthday at morning or afternoon tea. One group formed a jazz band, but commented that their gigs were not as favourably reviewed as their articles. One successful mentor noted that, having initially

created the social events, he/she now left it to the group, with a resulting range of events that reflected their interests from canoeing to cake-baking to karaoke.

\section{Skill development}

CCM has focused on equipping people with the skills to be fully functioning members of the scientific community, able to prepare grant applications, review manuscripts, speak at conferences and engage with scientific administrators in a constructive manner. Such a holistic approach to running a scientific group will ultimately bring enormous benefit to the group's alumni, giving them all the skills necessary to carve out their own niches in the academic world. $)$

It is clear that successful mentors work hard at developing the scientific skills of their charges. Again this depends on deliberate strategies and activities rather than leaving the outcome to chance. Not surprisingly, the following three skills were the ones that were most often commented on.

\section{Criticism}

CCOur regular meetings would often entail

the discussion and evaluation of recent published works. This process provided a great insight into the method of critiquing and assisted in driving our work into new methodological areas to answer questions in a greater depth. $\mathbf{s}$

\section{CCThe critical analysis of scientific publications is encouraged. No conclusions are taken at face value and fearless discussion of the analysis and interpretation of results takes place during our weekly laboratory meetings and, of course, in the preparation of papers. 99}

Again this is where a journal club has been used to good effect - students regularly take turns dissecting one or two relevant current papers and their background, with input from other students and faculty members. The successful strategies highlighted involve requiring students or young colleagues to write reviews of journal articles, referees' reports and grant applications and then critiquing their efforts.

Instinctively you probably know the value of such activities, but do you always ask for individuals or groups of staff/students to have a go first? Or do you simply involve them in critiquing your writing or your grant application? The last approach is not the way that works.

\section{CCM does not only guide his students in their research, but ensures that they learn how to critically review the literature. He often challenges his students with an exercise of reviewing a paper. He then patiently remarks on their review. $)$}

As this quote illustrates, another way these activities benefit science is by preparing the mentees for their role as peer reviewers in the future. This is an activity often taken for granted. We believe that it shouldn't be. Peer review is all too easily done badly, and is also all too easily put aside under the pressure of other commitments.

It is essential that the motivation to review papers and grant applications is instilled in young scientists. It is equally essential that they be required to practise such activities, under the scrutiny of their mentor. Only then are they likely to learn how to provide a combination of specific and constructive advice about significance, technical strengths and weaknesses, and (for papers) presentation (see Editorial, page 754.)

\section{Writing}

CCWriting my first paper was a true experience. $M$ asked me to write it, but the paper that was submitted had no resemblance to my initial written draft. Nevertheless, $M$ went through my mistakes patiently and thoroughly, a writing experience from which I learned a great deal. This paper was accepted by Cell without any corrections, which is a very rare event. 99

Writing is such a critical part of being a scientist that its development must not be taken for granted. Among outstanding mentors, rapid turnaround over one to two days with clear feedback seemed the norm, as did resisting the temptation to do the rewrite for the student but, rather, assisting the mentees to rewrite several times. Also, it seems essential that this attention is paid to writing from the very beginning of a studentship. This requires deliberate action and tasksetting by the mentor.

\section{Oral presentation}

CCAlthough few students have a natural gift for giving a scientific talk, all can learn if given sufficient practice and advice. I always suggest that the student provides me with a run-through a week or two before 
a presentation, to allow sufficient time for revisions. 95

$\mathbf{C} /$ recall that one day $M$ suggested that she and I should have a wager on who could ask the best question of the speakers at the chemistry seminars held weekly in the department. This meant you had to listen closely to the work being presented and to think about it, in order to come up with an insightful question. I recognized that what she really wanted to do was show the students how to get involved in a seminar and she used us as examples of how to engage with the topic presented. Her questions were always informal but probing. The audience, largely made up of postgraduate students in chemistry, of course loved this and soon got into the act. 99

The quotes speak for themselves, but all mentors saw it as their role to ensure that their charges had ample opportunity to speak at international forums, and all highlighted the need for practice and critique beforehand. An often-neglected skill is the art of questioning as described in the second quote about the practice of an experienced mentor.
When it came time to leave his laboratory and develop links with others, $M$ was a great source of contacts and ideas. $)$ that their charges were exposed and introduced to visitors who came into a laboratory. And they encouraged collaboration by introducing their mentees to potential collaborators. This was never left to chance but was planned.

\section{CSimilarly another practice was to try to secure a few hours of time from visiting international scientists during which students would present their work. This practice has a number of benefits. First it provided good-quality feedback and a range of helpful suggestions on the direction of particular pieces of research. Second, and perhaps of particular importance to Australian trainees, this practice gave an insight into the way some of the world's outstanding researchers think and helped demystify the work of such researchers. $)$}

Departmental tradition often expects the visiting scientist
All the mentors made special efforts to ensure

conferences and/or visit the laboratories of colleagues in their networks. Some unselfishly suggested that their protégés should go instead of themselves. Others, when overseas, ensured that they arranged exposure of the work of their charges to world experts. Hence:

CSShe would attend conferences with her students and at such events would always make a point both of introducing her students to the leaders in the field, and of actively encouraging anyone to whom she was talking to go and see the students' work. She was renowned for arriving at her students' or postdocs' posters with a bemused world-expert in tow and then encouraging the student to explain the poster, letting the student do the talking but with $M$ adding encouraging and supportive comments from the sideline. This is another practice I have adopted from $M .25$

Once aspiring young mentors appreciate just how important it is for all their students/staff to have opportunity to travel, it is important to negotiate financial support from the depart-

ment or professional society or elsewhere.

There are sources of funding available, and good mentors seek these out, just $\sum_{\infty}$ as they actively look around to find the best match of conference and/or laboratories for their mentees.

\section{Advice on career decisions} CCBut perhaps the most important thing is his tireless attention to the needs and in particular the career development of the younger people around him. M always finds top placements for his students and postdocs. 9

Perhaps a defining feature of the Nature nominees was that the goal of networking
All successful scientists have extensive networks spread across the globe. But do they all link their students into those networks as actively as they could? This was another of the standout attributes of the Nature finalists and, as commented on above, is one of the distinguishing features of a mentor over someone who is simply a good supervisor. Good mentors saw it as their responsibility to share their network.

\section{Use their contacts and promote their students/young staff}

CCM always made a large effort to develop the scientific careers of his students. He would actively encourage his students to attend national and international conferences and at these conferences would make a significant effort to introduce his students to other a great effort to make sure others were aware of his students' achievements and work.

\section{Networking} researchers in their field. He would also make to present his or her findings to the department. Good mentors ensure that the visitor also gets to hear of the work of their students and staff.

As support for those who have left the laboratory continues, the advice of one mentor rings very true:

CCWrite only honest references. One slanted recommendation will damage the prospects of all that follow, because the writer's credibility goes out of the window. $\$$

\section{Send overseas}

CCWith the wisdom of hindsight, I think the single most important thing I did as supervisor of PhD students was to send each one of them overseas at least once in their candidature. 99

Another recurring theme was gratitude from the mentees at the special efforts their mentors made to allow them to travel overseas to was not simply linked to their own research progress, or to ensure that the $\mathrm{PhD}$ was successful, or that the work of the postdoc or research assistant moved their projects forward. Rather, there was evidence of extensive communication, discussion and negotiation behind the scenes to ensure that when the student or colleague left the group they could travel along a pathway that was most likely to set them on a successful career. All the supporting mentees had successful careers and in all cases their mentor had helped them with their career.

\section{Conclusion}

cCHaving a good mentor early in one's career can mean the difference between success and failure in any career. $\boldsymbol{9}$

CCThose who are good mentors get incalculably more out of it than they put into it. 95 
Self-assessment: how good a mentor are you?

\begin{tabular}{|c|c|c|c|}
\hline Activity/Strategy & Question/Task & Example & What could be done better? \\
\hline $\begin{array}{l}\text { Appreciating individual } \\
\text { differences }\end{array}$ & $\begin{array}{l}\text { Give an example of an } \\
\text { incident that illustrates your } \\
\text { acknowledgement of individual } \\
\text { difference }\end{array}$ & & \\
\hline Availability & $\begin{array}{l}\text { Give an example of the strategy } \\
\text { you use to be available to your } \\
\text { students/staff }\end{array}$ & & \\
\hline Self-direction & $\begin{array}{l}\text { What was your rating on the } \\
\text { scale on page } 793 \text { ? }\end{array}$ & & \\
\hline Questioning & $\begin{array}{l}\text { Describe how you last used } \\
\text { active questioning to lead a } \\
\text { mentee towards a solution }\end{array}$ & & \\
\hline Celebration & $\begin{array}{l}\text { When did you last celebrate } \\
\text { a student/staff member's } \\
\text { achievement? How did you } \\
\text { celebrate? }\end{array}$ & & \\
\hline Building a scientific community & $\begin{array}{l}\text { Describe a deliberate strategy } \\
\text { you use to build a scientific } \\
\text { community in your group }\end{array}$ & & \\
\hline Building a social community & $\begin{array}{l}\text { Describe a deliberate strategy } \\
\text { you use to build your group as a } \\
\text { social community }\end{array}$ & & \\
\hline Skill development & $\begin{array}{l}\text { Describe steps you take to } \\
\text { develop the critical, writing } \\
\text { and presentation skills of you } \\
\text { students/staff }\end{array}$ & & \\
\hline Networking & $\begin{array}{l}\text { Describe one example of how } \\
\text { you have introduced each of } \\
\text { your students/staff into the } \\
\text { scientific network of your } \\
\text { research area }\end{array}$ & & \\
\hline Mentor for life & $\begin{array}{l}\text { How many of your past } \\
\text { students/staff are you in } \\
\text { contact with? }\end{array}$ & & \\
\hline $\begin{array}{l}\text { What one thing will you do } \\
\text { differently after reading the } \\
\text { description of the mentoring } \\
\text { behaviour of the Nature mentors? }\end{array}$ & & & \\
\hline
\end{tabular}

This article concludes as it starts, with reference to just how important mentoring is to those under your care. The second quote highlights the positive satisfaction of being a good mentor.

From the entries we have read, it is clear that there are second generations of mentors now out there who learnt from their own mentors how to provide superb support for the scientists under their charge. Many reading these pages will themselves have been privileged to have been mentored by those applying many of the strategies described. Indeed, in the pages of nominations that was the inspiration for this article, it was also clear that the proposing mentees had taken on board the behaviours of their mentor and were themselves well on the way to being the next generation of successful mentors.

Our purpose, based on the rich resource provided by both mentees and mentors, is to challenge you to reflect on how you are currently mentoring those under your charge. Is there anything you can learn? More importantly, can you improve what you do? What examples of exemplary mentoring activities do you use?

Equally important, for those young scientists newly embarked on a career in science or about to start building a research team: can you plan your approach to mentoring that team by including strategies, processes and behaviours described here that clearly work? If so, you will not only influence the next generation of scientists but also increase your own satisfaction by being in charge of a productive, enthusiastic, challenging and fun team.

As a stimulus to these reflections, we have drawn up a simple table (above) designed to aid your reflections. Whether you are setting out on a mentoring pathway or simply want to see how your mentoring strategies stand up, we encourage you to fill out the table. It asks for the provision of specific examples: we consider this to be the best way to stimulate reflection on your approach to scientific mentoring.

Just as the values and strategies of the great mentors, nominated for the Nature awards, have benefited the careers of hundreds of now successful scientists, we hope that this distillation of approaches will have a beneficial effect on your mentoring of our future successful scientists.

\section{Adrian Lee was pro-vice-chancellor} (education and quality improvement) at the University of New South Wales, Australia, from 2000 to 2006.

Carina Dennis is Australasian correspondent of Nature.

Philip Campbell is editor-in-chief of Nature, and founded the Nature mentoring awards. 